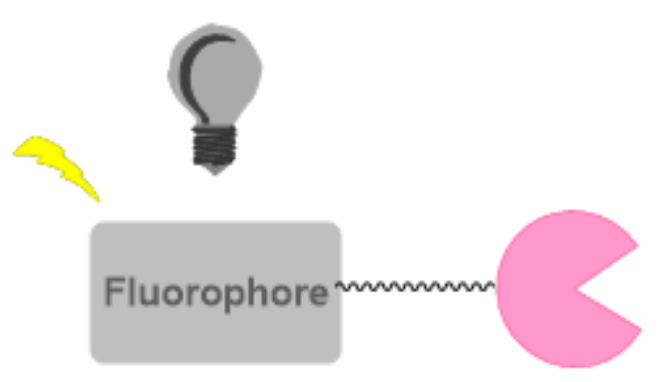

Fluorescent Probe

OFF

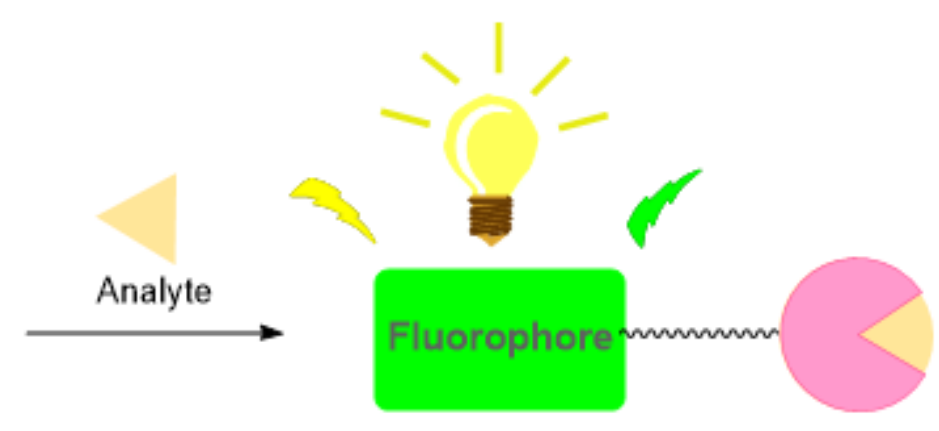

Fluorescent Probe

\title{
ON
}

\section{FLUORESCÊNCIA: PRINCÍPIOS E ALGUMAS APLICAÇÕES}

\author{
Beatriz S. Cugnasca*, Alcindo A. Dos Santos ${ }^{\text {a }}$ \\ ${ }^{a}$ Instituto de Química, Universidade de São Paulo (USP), 05508-000, São Paulo - SP, Brasil. \\ beatriz.cugnasca@usp.br
}

\begin{abstract}
Resumo: A fluorescência vem sendo bastante estudada nos últimos tempos tendo grande relevância em muitas áreas com aplicações em diversos segmentos, tais como diagnósticos clínicos, detecção de analitos, biotecnologia, imageamento celular e molecular, química forense, teranóstica, entre outras. Devido à versatilidade e facilidade de modificação estrutural, elevada sensibilidade e rápido tempo de resposta, os sensores fluorescentes acabam sendo muito utilizados como biomarcadores, podendo auxiliar no diagnóstico de doenças. Nesta resenha iremos abordar os fundamentos básicos da fluorescência, bem como seu uso como sensores fluorescentes, buscando apresentar alguns exemplos de aplicações e a sua importância na detecção de analitos em sistemas biológicos.
\end{abstract}

Palavras-chave: fluorescência, sensores fluorescentes, fotoluminescência, sistemas biológicos.

\section{FLUORESCENCE: PRINCIPLES AND SOME APPLICATIONS}

Abstract: Fluorescence has been widely studied in recent times, having great relevance in several areas such as clinical diagnosis, analyte detection, biotechnology, cell and molecular imaging, forensic chemistry, theranostics, among others. Due to their versatility and easy of structural modification, high sensitivity, and fast response time, fluorescent sensors have been widely used as biomarkers and can help in the diagnosis of diseases. In this mini-review we will present the basics of fluorescence, as well as its use for fluorescent sensing, seeking to present some examples of applications and their importance in the detection of analytes in biological systems.

Keywords: fluorescence; fluorescent sensors; photoluminescence, biological systems.

\section{Introdução}

Luminescência é o fenômeno de emissão de radiação por determinadas substâncias, a partir de um estado eletrônico excitado. ${ }^{1}$ Este pode ser atingido através de diferentes modos de excitação (estímulos), que são utilizados como critérios de classificação da luminescência. Ela pode ser dividida em: bioluminescência (estímulo por reações bioquímicas), quimiluminescência (estímulo por reações químicas), eletroluminescência (estímulo elétrico), termoluminescência (estímulo 
térmico) e fotoluminescência (estímulo por absorção de luz, no qual se inserem os conceitos de fluorescência e fosforescência), entre outros tipos. ${ }^{1,2}$

A fluorescência, de modo geral, é o fenômeno de emissão de luz por determinadas substâncias quando expostas à radiação eletromagnética. ${ }^{3}$ Este fenômeno está diretamente envolvido na resposta dos sensores fluorescentes. Nos últimos anos a fluorescência vem sendo amplamente explorada em diversas áreas como para detecção de analitos (espécies oxidantes, íons metálicos, aminoácidos, entre outros), ${ }^{4-6}$ biotecnologia, diagnósticos clínicos, imageamento celular, sequenciamento de DNA, biomarcação de proteínas, citometria de fluxo, química forense, teranóstica, análises genéticas, entre outras aplicações. ${ }^{7}$

\section{Breve histórico sobre fluorescência}

Em 1565, o botânico Nicolas Monardes descreveu pela primeira vez a emissão de fluorescência, relatando o surgimento de uma coloração azul intensa emanada de uma infusão aquosa de uma árvore mexicana (Eysenhardtia polystachya), utilizada na época para o tratamento de doenças renais, ${ }^{1}$ ficando conhecida como Lignum nephriticum (madeira de rim). ${ }^{2,8-10}$ As propriedades observadas foram, posteriormente, estudadas por outros cientistas, estando entre eles Newton, Kircher, Grimaldi e Boyle. ${ }^{8}$ Em 1845, John Herschel estava realizando estudos utilizando soluções de sulfato de quinina e observou o fenômeno de emissão de luz por parte da solução, denominando na época como um processo de refrangibilidade da luz. ${ }^{1,7,11,12}$ Em 1852, Sir George Stokes, um matemático e físico irlandês, deu continuidade aos estudos de emissão de luz utilizando soluções de sulfato de quinino e estabeleceu uma relação entre a absorção de luz com o fenômeno de emissão observado, cunhando, pela primeira vez, a palavra "fluorescência"., 1,2,7,12

Uma outra contribuição bastante importante na área foi realizada pelo físico polonês Alexander Jablonski, em 1933, ao propor a criação de um diagrama, conhecido atualmente como Diagrama de Jablonski, que permite explicar, por meio de níveis energéticos, os processos envolvidos na absorção e emissão de luz. .,2,7,13,14 $^{2}$

\section{Diagrama de Jablonski}

Estruturalmente, o Diagrama de Jablonski é constituído por estado eletrônico singleto não excitado $\left(S_{0}\right)$, estados eletrônicos singleto excitado $\left(S_{1}\right.$ e $\left.S_{2}\right)$ e estado eletrônico tripleto excitado $\left(\mathrm{T}_{1}\right.$ ) (Figura 1). Em cada um desses estados eletrônicos existem níveis vibracionais, sendo esses subníveis classificados pelos números quânticos: $0,1,2,{ }^{7}$ Quando um fluoróforo é exposto à uma radiação eletromagnética, o mesmo pode absorver luz passando do estado eletrônico $S_{0}$ para um dos estados eletrônicos excitados $\mathrm{S}_{1}$ ou $\mathrm{S}_{2}$. Esse processo de absorção de luz ocorre muito rapidamente, sendo da ordem de $10^{-15}$ segundos. Quando no estado eletrônico excitado, pode ocorrer a relaxação vibracional, um processo de transição não radiativa, sendo uma transição de um nível vibracional de maior energia para outro de menor energia dentro de um mesmo estado eletrônico excitado. Um outro processo de transição não radiativa é o da conversão interna (CI). Este ocorre quando se tem uma transferência de um estado eletrônico excitado singlete para outro estado eletrônico excitado de mesma multiplicidade de spin. Quando no menor nível vibracional do estado eletrônico excitado $\mathrm{S}_{1}$, pode ocorrer retorno para um dos níveis vibracionais do estado eletrônico fundamental $\mathrm{S}_{0}$, por meio de uma transição radiativa, sendo esse processo denominado fluorescência. Este fenômeno está diretamente envolvido nas respostas dos sensores fluorescentes, que serão abordados aqui. Vale 
ressaltar que os processos não radiativos (conversão interna e relaxação vibracional) ocorrem em um tempo da ordem de $10^{-12}$ segundos, sendo este menor que o da fluorescência $\left(10^{-8}\right.$ segundos). ${ }^{7}$ Dessa forma, eles tendem a acontecer anteriormente à emissão, de modo que ela se processe a partir do menor nível vibracional do estado eletrônico excitado $S_{1}$, e não dependa do comprimento de onda de excitação na grande maioria das vezes (regra de Kasha) ${ }^{7,15}$

Em alguns casos, pode ocorrer o processo denominado de Cruzamento Intersistemas (CIS), no qual se tem transição não radiativa do estado eletrônico excitado singleto $\left(\mathrm{S}_{1}\right)$ para algum nível vibracional isoenergético do estado eletrônico excitado tripleto $\left(\mathrm{T}_{1}\right)$ envolvendo mudança de spin. A partir do estado $\mathrm{T}_{1}$ pode ocorrer emissão sendo esse processo denominado fosforescência $\left(10^{-3}-10^{0}\right.$ segundos), apresentando, no geral, maiores valores de comprimento de onda quando comparado com a emissão de fluorescência. Apesar de ser uma transição proibida, ela pode ocorrer devido ao acoplamento spin-órbita, sendo favorecido em compostos contendo átomos pesado, como bromo ou iodo. Temperaturas baixas e solventes com maior viscosidade tendem a favorecer a ocorrência da fosforescência. ${ }^{7}$

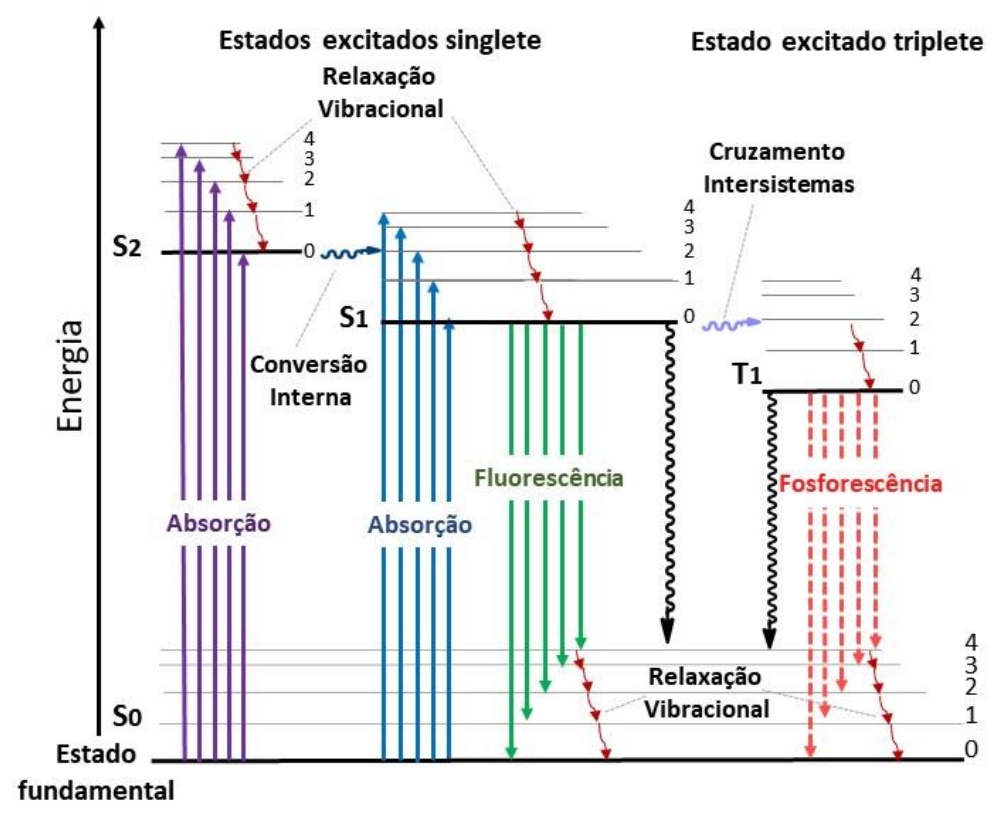

Figura 1. Representação esquemática do Diagrama de Jablonski

Nos últimos anos se observou um crescimento na procura, desenvolvimento e no uso de técnicas baseadas na fluorescência como ferramenta analítica em diversas áreas do conhecimento, ${ }^{2,7}$ como biotecnologia, biologia molecular, análises clínicas e toxicológicas, entre outras. Dentre as principais técnicas laboratoriais encontram-se microscopia confocal ${ }^{16}$ e microscopia de fluorescência, ${ }^{17}$ imunofluorescência, ${ }^{18}$ citometria de fluxo, ${ }^{19}$ imunoensaios por fluorescência, ${ }^{20,21}$ PCR em tempo real ${ }^{22}$ (uso de sensores fluorescentes no PCR tradicional), entre outras áreas.

\section{Fundamentos básicos da fluorescência}

Os estudos fotofísicos de compostos fluorescentes geralmente se iniciam por meio da obtenção de espectros de absorção, excitação e emissão de fluorescência, a partir dos quais 
parâmetros espectrais como valores de comprimentos de onda de máxima absorção ( $\left.\lambda_{\text {abs }}\right)$ e emissão $\left(\lambda_{\mathrm{em}}\right)$, coeficiente de absortividade molar $(\varepsilon)$ e intensidade de emissão de fluorescência são obtidos, além de ser possível avaliar a pureza dos compostos em estudo. A lei de Beer-Lambert (Equação 1) ${ }^{1}$ pode ser utilizada para descrever o processo de absorção uma vez que correlaciona a quantidade de luz que é absorvida pela amostra com a sua concentração, caminho óptico e a absortividade molar:

$$
\mathbf{A}=\boldsymbol{\varepsilon} \cdot \mathbf{b} \cdot \mathbf{c} \quad(\text { Equação } 1)
$$

onde $\mathbf{c}\left(\mathrm{mol} . \mathrm{L}^{-1}\right)$ é a concentração da amostra, $\boldsymbol{\varepsilon}$ é o coeficiente de absortividade molar $\left(\mathrm{L} \cdot \mathrm{mol}^{-1} \cdot \mathrm{cm}^{-}\right.$ $\left.{ }^{1}\right)$ e b é o comprimento do caminho óptico $(\mathrm{cm})$.

Após a absorção de luz, perdas de energia podem ocorrer através de processos não radiativos, como relaxação vibracional e conversão interna. Dessa forma é esperado que o espectro de emissão de fluorescência seja observado em comprimentos de onda maiores do que o comprimento de onda de excitação. Assim, a diferença entre os comprimentos de onda $\lambda_{\text {abs }}$ e $\lambda_{\text {em }}$ é denominada de Deslocamento de Stokes, ${ }^{1,7}$ podendo ser representada pelo símbolo: $\Delta \lambda$ (Figura 2).

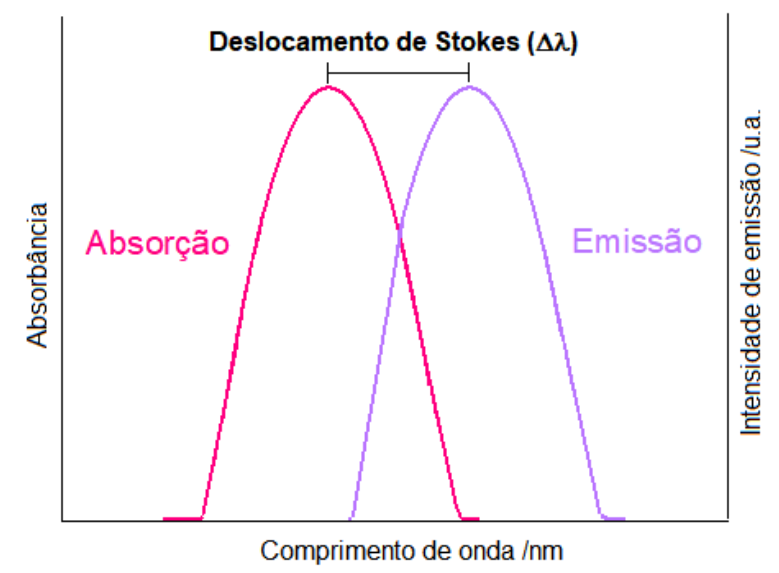

Figura 2: Desenho representativo de espectros de absorção e emissão destacando o Deslocamento de Stokes

Como já mencionado, sabe-se que existe uma competição entre o processo de transição por meios radiativos e não radiativos. Nesse contexto, o conceito de Rendimento Quântico de Fluorescência $(\Phi)$ é utilizado, sendo definido como a razão entre o número de fótons emitidos pelo número de fótons totais absorvidos. Um outro conceito bastante utilizado é o de tempo de vida de fluorescência $(\tau)$, sendo correspondente ao tempo de vida em que o composto fluorescente permanece no estado excitado antes de retornar para o estado fundamental. ${ }^{1,2,7}$

\section{Sensores fluorescentes}

A emissão de fluorescência pode ser modulada por meio de alterações químicas na estrutura de determinado composto fluorescente ou por meio de variações de parâmetros do meio em que ocorre o fenômeno, como por exemplo temperatura, $\mathrm{pH}$, viscosidade e polaridade do solvente. ${ }^{23-25}$ Entre os diversos métodos de detecção de analitos, os sensores fluorescentes vêm sendo bastante 
utilizados como biomarcadores devido à facilidade de modificação estrutural, elevada sensibilidade e rápido tempo de resposta. ${ }^{26}$ Eles podem auxiliar na descoberta de novos medicamentos, na obtenção de imagem celular, no diagnóstico de doenças, além de permitir o monitoramento em tempo real de diversos analitos. ${ }^{27}$ Dessa forma o interesse no desenvolvimento de novos sensores fluorescentes tem se intensificado nos últimos anos.

Estruturalmente, os sensores fluorescentes são compostos constituídos por uma unidade receptora, responsável pela interação com o analito e uma porção fluorofórica, responsável pela emissão da fluorescência. Quando na presença de um analito, este pode interagir com a porção receptora do sensor de modo que uma resposta devido à essa interação seja obtida na forma de fluorescência. Essas respostas, por sua vez, podem ser quantificadas por meio da obtenção de espectros de emissão e rendimento quântico de fluorescência. ${ }^{28}$ Após estudos fotofísicos, testes in vitro e in vivo podem ser realizados, buscando-se aplicações em sistemas biológicos.

\section{Aplicações em sistemas biológicos}

Os sensores fluorescentes vêm sendo amplamente utilizados atualmente na detecção de diversos analitos, como íons metálicos, espécies reativas de oxigênio (EROs) ou nitrogênio (ERNs), ${ }^{4}$ alguns aminoácidos, além de poderem auxiliar no diagnóstico de doenças ou até mesmo para finalidades terapêuticas. ${ }^{29,30}$

A detecção de cátions metálicos em sistemas biológicos é de bastante relevância uma vez que os mesmos, quando em excesso ou falta no organismo podem estar associados à processos patológicos, já que esses íons participam de diversos processos bioquímicos de regulação e sinalização. Além disso, o monitoramento desses cátions nas células, órgãos e tecidos auxiliam no diagnóstico e no estudo de doenças. ${ }^{31}$ Um exemplo de grande importância é a detecção de íons $\mathrm{Cu}^{2+}$ em células. O cobre é um elemento que está relacionado a certos processos fisiológicos, atuando como cofator de enzimas essenciais do metabolismo. Um desequilíbrio na concentração de cobre nas células pode ocasionar doenças cardíacas, doenças neurodegenerativas, como Alzheimer e Parkinson, além de poder levar a distúrbios gastrointestinais e danos no fígado e rim. ${ }^{32-35}$ Sendo assim, o desenvolvimento de sensores fluorescentes para a detecção de $\mathrm{Cu}^{2+}$ é bastante importante. Em 2018, um sensor fluorescente ratiométrico constituído de uma Rodamina 6G e de 2formilanilina, conectadas por uma hidrazina, foi sintetizado (Figura 3). ${ }^{35}$ Ele apresentou elevada seletividade para íons $\mathrm{Cu}^{2+}$ frente a outros 15 cátions, sendo os estudos conduzidos por meio da obtenção de espectros de absorção e emissão de fluorescência. Quando na ausência de íons $\mathrm{Cu}^{2+}$, o composto apresenta emissão em $450 \mathrm{~nm}$, sendo correspondente à porção constituída pela formilanilina. No entanto, conforme se adiciona íons $\mathrm{Cu}^{2+}$ na solução, a intensidade de emissão de fluorescência em $450 \mathrm{~nm}$ sofre um decréscimo enquanto que um novo pico de emissão surge no comprimento de onda de $546 \mathrm{~nm}$, devido à abertura do anel espirocíclico da rodamina $6 \mathrm{G}$ quando na presença do cátion, com um rendimento quântico de 0,33 . O sensor apresentou limite de detecção de $4,2.10^{-7}$ mol.L $\mathrm{L}^{-1}$ e estudos em células foram realizados, mostrando que o mesmo pode ser utilizado de forma eficiente como um biomarcador para íons cobre (II). Os autores mostraram que o processo é reversível, pela adição de EDTA à solução, que complexa, seletivamente os íons $\mathrm{Cu}^{2+}$, regenerando a estrutura molecular original (1), emissiva, em apenas um comprimento de onda (450 nm). 


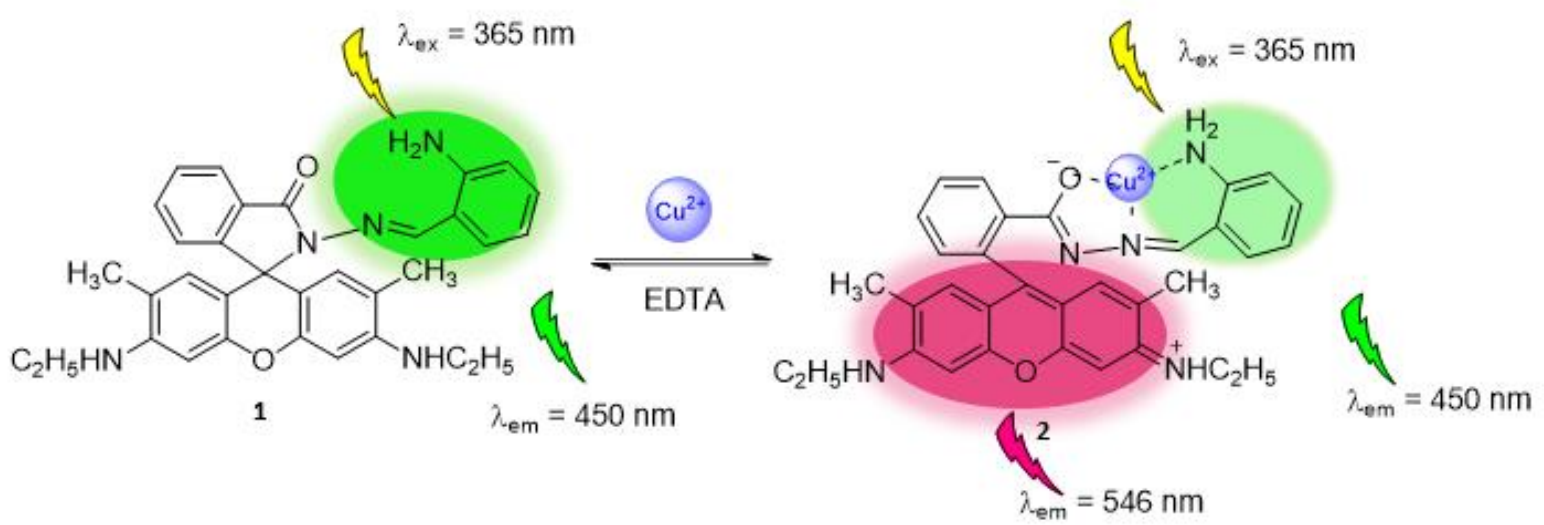

Figura 3: Sensor fluorescente à base de Rodamina utilizado para detecção ratiométrica de íons $\mathrm{Cu}^{2+}$ (Adaptada de Sikdar, A., et. al., 2018) $)^{35}$

Além de íons metálicos, muitos sensores fluorescentes vêm sendo desenvolvidos com o intuito de detectar de espécies reativas de oxigênio (EROs). A mitocôndria tem um importante papel na produção dessas espécies. Elas estão associadas às funções fisiológicas de sinalização celular, síntese de biomoléculas e ao sistema de defesa do organismo. No entanto, quando em condições de estresse oxidativo, elevadas concentrações de EROs no organismo podem levar a danos celulares, podendo estar associado às doenças ou desordens como diabetes, câncer, neurodegeneração, entre outras. ${ }^{36,37}$ Dessa forma, a detecção dessas espécies em sistemas biológicos é bastante importante.

Em 2019, um teluro-BODIPY (3), que foi empregado como sensor fluorescente de EROs foi sintetizado (Figura 4). O composto apresentou capacidade de detecção rápida e seletiva para hipoclorito. ${ }^{38}$ Estudos de emissão de fluorescência foram conduzidos e observou-se que o BODIPY, quando na presença do analito apresentava fluorescência verde intensa, que pode ser explicada pela oxidação do telúrio ao correspondente teluróxido. Foi obtida uma correlação linear entre a intensidade de emissão de fluorescência e a concentração de hipoclorito $\left(0-8 \mu \mathrm{mol} . \mathrm{L}^{-1}\right)$ apresentando um limite de detecção de $0,12 \mu \mathrm{mol} . \mathrm{L}^{-1}$. Além disso, estudos em células foram realizados com auxílio da microscopia confocal de fluorescência, permitindo a aplicação do sensor, na detecção deste EROs, em sistemas biológicos.
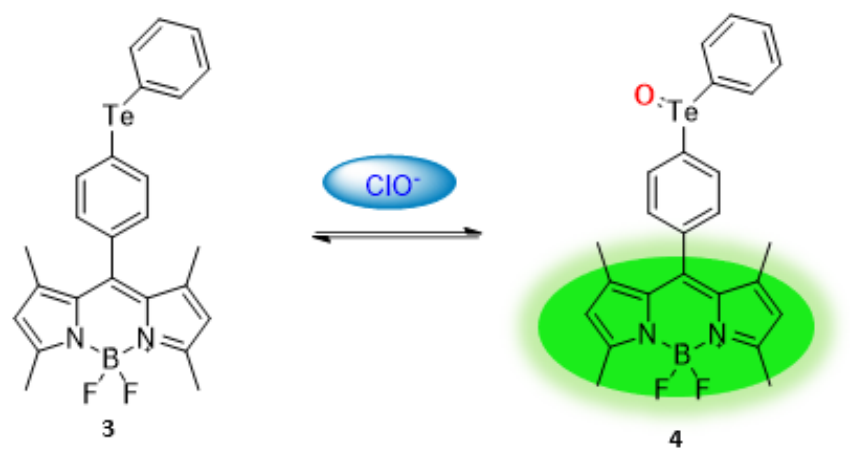

Figura 4: Sensor fluorescente a base de teluro-BODIPY utilizado para detecção de hipoclorito (Adaptada de Shi, W., et. al., 2019) $)^{38}$ 
Uma outra abordagem é a do uso de sensores fluorescentes na detecção e quantificação de tióis endógenos, como a glutationa. Um grupo de pesquisadores chineses desenvolveu um sensor à base de cumarina capaz de detectar glutationa (GSH) especificamente, por fluorescência (Figura 5). ${ }^{39}$ Devido à presença de um átomo pesado como o $\mathrm{Br}$, o sensor 5 não apresenta fluorescência. No entanto, quando na presença de tióis como a glutationa, o bromo acaba sendo substituído, dando lugar ao composto 6, fluorescente. No caso de biotióis, como cisteína ou homocisteína, a extremidade livre contendo um grupo $\mathrm{NH}_{2}$ é capaz de reagir com a carbonila, resultando nos compostos $\mathbf{7}$ ou $\mathbf{8}$, que apresentam fluorescência apenas moderada. Dessa forma, o sensor $\mathbf{5}$ apresentou uma boa seletividade para glutationa frente a outros possíveis interferentes biológicos, estando entre eles outros compostos contendo também grupos $\mathrm{SH}$, como cisteína e a homocisteína. Estudos com células também foram realizados permitindo a detecção de glutationa em sistemas biológicos.

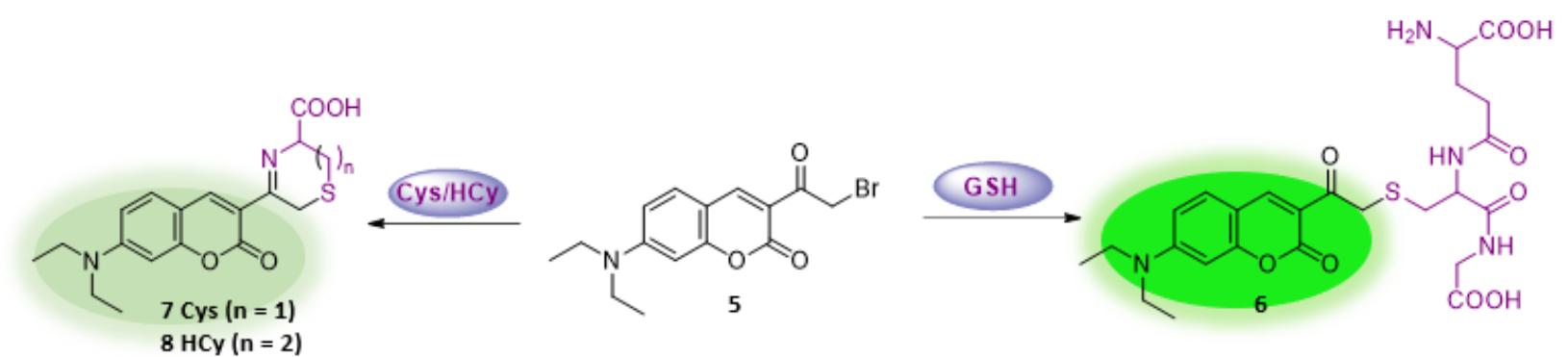

Figura 5: Sensor fluorescente a base de cumarina utilizado para detecção de glutationa. (Adaptada de He, L., et. al., $2015)^{39}$

\section{Considerações finais}

A fluorescência é um fenômeno de emissão de luz que vem sendo amplamente explorado nos últimos anos estando presente em diversas técnicas laboratoriais como PCR em tempo real, microscopia confocal e microscopia de fluorescência, imunoensaios, citometria de fluxo, entre outros. É uma ferramenta analítica poderosa e de utilização ampla para diversas aplicações. Por se tratar de um fenômeno que pode ser modulado, em função da estrutura de compostos que apresentam tais fatores, a síntese de novos sensores fluorescentes é um ramo da química de intensa investigação e grande interesse, abrindo horizontes na construção de dispositivos seletivos para a detecção de analitos variados e compreensão de fenômenos biológicos complexos.

Como pretendíamos demonstrar, os sensores fluorescentes encontram utilização em vários setores, permitindo, desde a simples detecção de um analito ambiental, como um cátion metálico, à eventos biológicos altamente complexos e difíceis de serem mensurados por outras técnicas. Pela fluorescência tem sido possível realizar, em tempo real, o imageamento de eventos biológicos in vivo, de elevada complexidade, abrindo aos olhos de cientistas, fenômenos antes apenas conjecturados e outros até então desconhecidos. 


\section{Agradecimentos}

Os autores agradecem à FAPESP (2019/07634-1 e 2018/24434-3) e ao CNPq (141855/2019-3) pelo suporte financeiro. Agradecem também ao Instituto de Química da USP pela infraestrutura e suporte para o desenvolvimento das pesquisas realizadas no LabSSeTe.

\section{Referências}

1. Valeur, B.; Berberan-Santos, M. N. Molecular Fluorescence: Principles and Applications. John Wiley \& Sons, New Jersey: 2012.

2. Rezende, L. C. D.; Síntese, caracterização e aplicações de fluoróforos derivados do BODIPY. Tese de Doutorado, Universidade de São Paulo, Ribeirão Preto, 2016.

3. McNaught, A. D.; Wilkinson, A. IUPAC. Compendium of Chemical Terminology, (the "Gold Book”), $2^{\text {nd }}$ ed. Blackwell Scientific Publications, Oxford: 1997. Online version: 2019, created by Chalk, S. J. ISBN:0-9678550-9-8.

4. Wu, L.; Sedgwick, A. C.; Sun, X.; Bull, S. D.; He, X.; James, T. D. Acc. Chem. Res. 2019, 52(9), 2582-2597.

5. Chowdhury, S.; Rooj, B.; Dutta, A.; Mandal, U. Journal of Fluorescence, 2018, 28, 999-1021.

6. Zhou, Y.; Yoon, J. Chem. Soc. Rev., 2012, 41, 52-67.

7. Lakowicz, J. R.; Principles of Fluorescence Spectroscopy. $3^{\text {rd }}$ ed. Springer: New York. 2006.

8. Acuna, A. U.; Amat-guerri, F.; Early history of solution fluorescence: The Lignum nephriticum of Nicolás Monardes. In: Fluorescence of Supermolecules, Polymers, and Nanosystems. Springer-Verlag Berlin Heidelberg, 2008. p. 3-20.

9. Partington, J.R. Annals of Science 1955, 11, 1-26

10. Burns, D. T.; Dalgarno, B. G.; Gargan, P. E.; Grimshaw, J. Phytochemistry, 1984, $23(1), 167$.

11. Herschel, J. F. W. Philos. Trans. R. Soc. London 1845, 135, 143-145.

12. Stokes, G. G. Philos Trns R. Soc. London, 1852, 142, 463-562.

13. Jablonski, A. Nature, 1933, 131, n. 839, p. 21.

14. Jablonski, A. Z. Phys., 1935, 94, 38-46.

15. Kasha, M. Discussions of the Faraday Society, 1950, 9, 14-19.

16. Singh, A.; Gopinathan, K. P. Current Science, 1998, 74 (10), 841-851.

17. Masters, B. R. The Development of Fluorescence Microscopy. In: Encyclopedia of Life Sciences (ELS). John Wiley \& Sons, Chichester, 2010.

18. Coons, A. H.; Kaplan, M. H. The Journal of Experimental Medicine, 1950, 91(1), 1-13

19. Herzenberg, L. A. et. al. Clinical Chemistry, 2002, 48(10), 1819-1827.

20. Soini, E.; Hemmila, I. Clinical Chemistry, 1979, 25(3), 353-361.

21. Hemmila, I. Clinical Chemistry, 1985, 31(3), 359-370.

22. Heid, C. A. et. al. Genome Research, 1996, 6(10), 986-994.

23. Kim, J. S.; Quang, D. T.; Chem. Rev. 2007, 107, 3780-3799

24. Li, X.; Gao, X.; Shi, W.; Ma, H.; Chem. Rev. 2014, 114, 590-659.

25. Han, J.; Burguess, K. Chem Rev. 2010, 110, 2709-2728.

26. Han, H.; Jr, H. T.; Zang, Yi; Sedgwick, A. C.; Li, Jia; Sessler, J. L.; He, X.; James, T. D. Chem. Soc. Rev. 2021, 50, 9391-9429. 
27. Gao, L.; Wang, W.; Wang, X.; Yang, F.; Xie, L.; Shen, J.; Brimble, M. A.; Xiao, Q.; Yao, S. Q. Chem. Soc. Rev. 2021, 50 (2), 1219-1250.

28. Escudero, D. Acc. Chem. Res. 2016, 49, 1816.

29. Xing, J.; Gong, Q.; Akakuru, O. U.; Liu, C.; Zou, R.; Wu, A. Nanoscale, 2020,12, 2431124330.

30. Yan, C.; Zhang, Y.; Guo, Z. Coordination Chemistry Reviews 2021, 427, 213556.

31. Zheng, X.; Cheng, W.; Ji, C.; Zhang, J.; Yin, M. Reviews in Analytical Chemistry 2020, 39 (1), 231

32. Kuo,Y.; Zhou, M.; Cosco, B.; Gitschier, D. J.; Proc. Natl. Acad. Sci.USA 2001, 98, 6836-6841.

33. Strausak, D.; Mercer, J. F.; Dieter, H. H.; Stremmel, W.; Multhaup, G.; Brain Res. Bull. 2001, 55, 175-185;

34. Gaggelli, E.; Kozlowski, H.; Valensin, D.; Valensin, G. Chem. Rev. 2006,106, 1995-2044.

35. Sikdar, A.; Roy, S.; Mahto, R. B.; Mukhopadhyay, S. S.; Haldar, K.; Panja, S. S. Chemistry Select 2018, 3(46), 13103-13109.

36. Ray, P. D.; Huang, B.; Tsuji, Y. Cell. Signal. 2012, 24 (5), 981.

37. Lou, Z.; Li, P.; Han, K. Acta Physico-Chimica Sinica 2017, 33(8), 1573.

38. Shi, W.; Huang, Y.; Liu, W.; Xu, D.; Chen, S.; Liu, F.; Hu, J.; Zheng, L.; Chen, K. Dyes and Pigments 2019, 170, 107566.

39. He, L.; Xu, Q.; Liu, Y.; Wei, H.; Tang, Y.; Lin, W.; ACS Appl. Mater. Interfaces 2015, 7 (23), 12809. 